\title{
Differential encoding as a function of semantic polarity and form of visual stimulus presentation
}

\author{
ALAN J. BARNETT \\ State University of New York, Albany, New York 12208
}

\begin{abstract}
The present study investigated the saliency of form of visual stimulus presentation (printed word or picture) and of the semantic evaluative dimension (positive or negative) as encoding attributes for fifth-grade children. Three short-term memory trials within one visual form of presentation or one pole of the evaluative dimension were followed by a fourth short-term memory trial on which the stimulus material was shifted on one or both attributes (experimentals) or held constant (controls). The recall of the experimental groups consistently exceeded that of the control groups on the shift trial, providing evidence for a release from proactive inhibition and implying the saliency of both the form of visual stimulus presentation and the evaluative polarity of the stimulus concepts as encoding dimensions.
\end{abstract}

Wickens $(1970,1972)$ reviewed a line of research concerned with identifying the encoding categories of words following an adaptation of the Peterson and Peterson (1959) short-term memory situation. Keppel and Underwood (1962) had demonstrated a steady decline in recall from the first to the third or fourth trial and postulated proactive inhibition to be the cause. Wickens, Born, and Allen (1963) demonstrated that this proactive inhibition buildup does not generalize to material of a different class, and that shifting the class of material on a salient encoding dimension results in a marked increase in recall due to release from proactive inhibition. Wickens' $(1970,1972)$ review of a number of studies employing this method with adult subjects indicated that shifting on semantic attributes and representational forms resulted in a considerable amount of release from proactive inhibition.

The present study investigated the saliency of two attributes in the encoding processes of children. Those attributes (semantic and representational form) found most effective with adults were selected as the variables to be manipulated. To investigate variations in representational form, stimuli were presented either as pictures or as words. Wells (1973) demonstrated that the picture-word shift is effective in releasing proactive inhibition for adult subjects. In the present study, concepts which were picturable and readable to fifthgrade children were selected as the stimuli to be visually presented. These words were chosen from the DiVesta and Walls (1970) semantic differential norms

This paper is based on a doctoral dissertation submitted to the State University of New York at Albany. The author wishes to express his appreciation to Fred W. Ohnmacht, James Kuethe, John Rosenbach for their assistance, and to the administration and staff of the South Colonie Central Schools, Albany, New York for their cooperation. Requests for reprints of this study should be sent to Alan J. Barnett, Cerebral Palsy Treatment and Educational Facility, 314 South Manning Boulevard, Albany, New York 12208. for fifth-grade children. Although Wickens and Clark (1968) found that adult subjects encoded verbal material by some meaning characteristic associated with the extremes on each of the Osgood, Suci, and Tannenbaum (1957) dimensions, Pender (1969) found no effect when shifting on activity or potency for second- and sixth-grade children. While Pender (1969) found the evaluation dimension to be employed as a salient encoding category by second graders, Cermak, Sagotsky, and Moshier (1972) concluded that the ability to employ opposite values of the evaluation dimension (e.g., clean-dirty, happy-sad) to encode information for future retrieval appeared to develop between the fourth and sixth grades.

The variables of concern for the present investigation were form of visual stimulus presentation (picture or word) and evaluative rating (positive or negative). The short-term memory task followed the Peterson and Peterson (1959) paradigm involving four trials. The first three presented one form of stimulus presentation falling along the positive end of the evaluative rating scale, while the fourth trial exhibited a shift in the form of presentation, a shift in the polarity rating of the concepts presented, a shift in both dimensions, or no shift. The critical variable was the effect that shifting form and/or polarity had on the release of proactive inhibition which had been expected to build up across the first three trials. It was hypothesized that release from proactive inhibition would be produced on Trial 4 when either the form, the polarity, or both were shifted. Such a shift was assumed to represent differential encoding based upon the psychological classes of form and polarity. Sufficient evidence (Pender, 1969; Wickens \& Clark, 1968) already exists for the symmetrical effect of variations in either direction along the evaluative dimension. Consequently, the present study attempted to demonstrate this symmetrical effect along the form of stimulus presentation 
dimension only. Although there was scant empirical ground upon which to base a prediction of the combined effect of shifting on both variables (Goggin \& Wickens, 1971; Hopkins, Edwards, \& Gavelek, 1971), the possibility of a double shift was examined.

\section{METHOD}

\section{Subjects}

The subjects were 40 male and 40 female fifth-grade children from a middle-class suburban school district (age range 125-153 months, mean age 132.40 months, KuhlmanFinch IQ range 88-124, mean IQ 109.66).

\begin{abstract}
Materials
Fifteen nouns were selected from the DiVesta and Walls (1970) norms. Twelve of these nouns were rated high on the evaluation scale (factor score $<41.00$ ) and three were rated low on the evaluation scale (factor score $>69.00$ ). These words were placed in groups of three and a $35-\mathrm{mm}$ color (red lettering on white background) slide was taken of each group. Four sets of groups of three were high evaluation (butterfly, fruit, man; money, home, flower; foot, church, puppies; kittens, apple, bed); one set was low evaluation (robber, fire, lion). The words were arranged vertically on each slide in a step fashion descending from left to right. Pictures of the objects named by the nouns were taken on $35-\mathrm{mm}$ color slides. The pictures were arranged in the same order and fashion as the words. In order to avoid semantic interference effects, no synonyms or antonyms of any of the words in the study were used.
\end{abstract}

\section{Apparatus}

The equipment used in the experiment consisted of a Carousel slide projector, a tape timer, a metronome, and $2 \times 2$ in. color photographic slides on which the experimental material was displayed.

\section{Procedure}

The procedure paralleled that of Wickens and Clark (1968). Each subject entered the test room individually and was randomly assigned to one of eight conditions. Five male and five female subjects served in each condition. These eight conditions were formed by the factorial combination of form of presentation (picture or word) on the first three trials, shift in form of presentation (present or absent) on Trial 4, and polarity shift (present or absent) on Trial 4.

AH materials were projected on a wall about $3 \mathrm{ft}$ in front of each subject. Following the presentation of an asterisk for $3 \mathrm{sec}$, the triad was presented for $3 \mathrm{sec}$. Then a numerical (three-digit) slide appeared, and the subject counted forward from a three-digit number to the beat of a metronome at a $1 \cdot \mathrm{sec}$ rate. The presentation times and counting procedure differed from those of Wickens and Clark (1968) to insure better performance on the part of subjects (Cann, Liberty, Shafto, \& Ornstein, 1973; Cermak, Sagotsky, \& Moshier, 1972). The three-digit numbers were selected so that a single digit never appeared in the same position in any three-digit sequence. At the end of $20 \mathrm{sec}$ of counting, a question mark signaled the end of the retention interval and the beginning of the $10 \mathrm{-sec}$ interval to recall the three words (or words for the three pictures). After an intertrial interval of $6 \mathrm{sec}$, an asterisk appeared for $3 \mathrm{sec}$ to serve as a ready signal for the next trial.

On the fourth trial the shifts were presented for the six experimental groups. The two control groups continued to receive three words or pictures conforming to the form and/or polarity of the first three trials.

Order of appearance of the triads was counterbalanced so that each group of words (or pictures) appeared equally

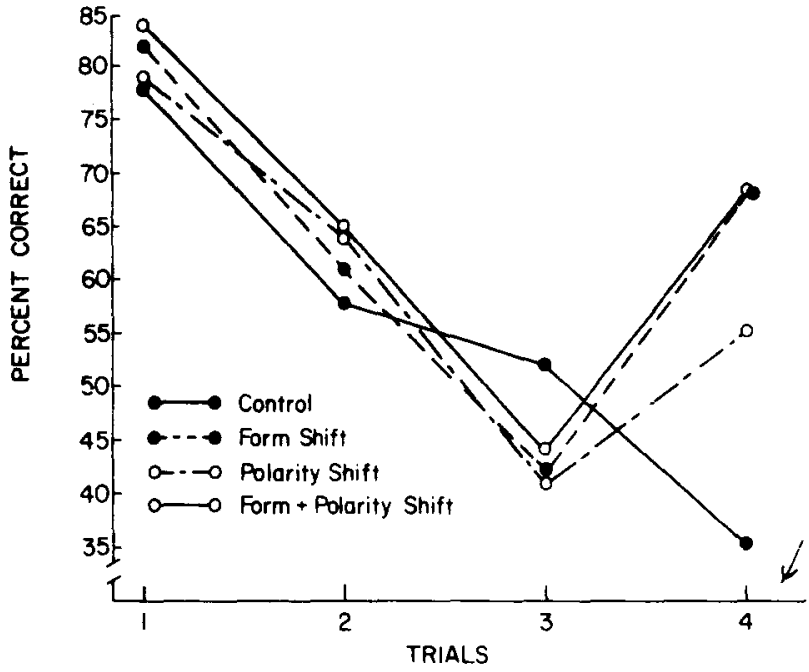

Figure 1. Across trials effect for all experimental and control groups.

often on each of the four trials for different subjects. The addition numbers were counterbalanced so that the same number neither fell in the same ordered position nor followed the same triad throughout the experiment. The response protocols were scored on a 4-point basis. One point was assigned if all three members of a triad were recalled in the same order as they had been presented.

\section{RESULTS}

The results of the experiment on the form of visual stimulus presentation shift, the polarity shift, and the double shift on both polarity and form are presented in Figure 1. As is usually true in this type of experiment, a reduction in accuracy of performance occurred progressively during the first three trials $[F(1,72)=$ 20.71, $\mathrm{p}<.005, \mathrm{MS}_{\mathrm{e}}=1.39$ ] for both the control and the experimental groups, followed by a marked increase in recall on the critical shift trial for the experimental groups. The control group continued to display a reduction in accuracy of performance on Trial 4.

A series of Neuman-Keuls comparisons (Winer, 1971) indicated that across the experimental conditions significant differences appeared between Trials 1 and 2, 1 and 3,1 and 4;2 and 3; and 3 and 4. Across the control conditions, significant differences appeared between Trials 1 and 2,1 and 3,1 and 4 ; and 2 and 4 .

The phrase "release from proactive inhibition" refers to the increment in recall following the shift on stimulus materials, and the percentage of release is calculated by determining the relationship between the improvement of the experimental groups on Trial 4 and the total decline of the control groups, expressed in percentage terms (Wickens, 1972). Accordingly, shifting from positive to negative polarity resulted in a $33 \%$ "release;" shifting the form of visual stimulus presentation resulted in a $61 \%$ release, and shifting on both form and polarity (the double shift) resulted in a $61 \%$ release. 
A series of Neuman-Keuls comparisons of Trial 4 performance for the four conditions indicated that the polarity-shift group, as well as the form-shift and doubleshift groups, did recall a significantly greater number of items than did the control groups on Trial 4. The picture presentations generally resulted in a greater number of correctly recalled items than did word presentations $\left[F(1,72)=11.11, \mathrm{p}<.005, \mathrm{MS}_{\mathrm{e}}=1.49\right]$. This resulted in a more marked effect of shifting from word to picture $(86 \%$ release) than vice versa ( $11 \%$ release) There were no higher order interactions to provide evidence of a multiple encoding effect.

IQ was found to have no bearing on the overall recall scores $(r=-.001)$. And sex was found not to be a critical variable in predicting overall recall score $[\mathrm{t}(78)=.349]$.

\section{DISCUSSION}

Results of the present study implied that the proactive inhibition effect demonstrated by Keppel and Underwood (1962) and reviewed by Wickens (1970, 1972) with adult subjects appeared when fifth-grade children served as subjects in a short-term memory task following the Peterson and Peterson (1959) paradigm. Release from proactive inhibition was produced on Trial 4 when either the form of visual stimulus presentation (picture/word) or the evaluative polarity (positive/negative) of the triads presented on the first three trials was shifted on the fourth trial between pictorial and visual-verbal. However, shifting on both form and evaluative polarity resulted in no increment (on Trial 4 recall) upon the effect of shifting the form of stimulus presentation alone.

The construct proactive inhibition has been postulated to account for the empirical phenomena in which items recalled prior to the recalling of items for which retention is being tested interfere with recall of the latter items following a retention interval (Keppel \& Underwood, 1962). As evidenced in Figure 1, the number of potentially interfering items and the amount of proactive inhibition are directly related. Thus, recall can be observed to decrease from Trial 1 to Trial 3 (and to Trial 4 in control conditions). Wickens, Born, and Allen (1963) have shown that this proactive inhibition buildup does not generalize to material of a different class. They interpreted this to mean that, in the short-term memory situation, triads of items, all elements of which are homogeneous with respect to a psychological class, are encoded not only as unique items but also as members of the same psychological class. Consequently, if the next item is drawn from a different class, then interference no longer exists or is minimized, and performance is raised (Wickens, 1970). The term "release from proactive inhibition" has come to represent this phenomenon of an increase in recall following a shift on a salient encoding dimension. Results of the present study imply that fifth-grade children have developed the ability to employ the form of visual stimulus presentation (picture or word) as an attribute salient to the encoding of information for future retrieval.

Although not as effective in demonstrating release from proactive inhibition, shifting on the evaluative polarity dimensions did result in release from proactive inhibition (33\%). Cermak et al. (1972) concluded that the ability to employ opposite values of the evaluation dimension to encode information for future retrieval appears to develop between the fourth and sixth grades, while Pender (1969) contended that the evaluation dimension is employed as a salient encoding category by second graders. There are a number of methodological differences between each of these studies and the present study including variations in the marking syntactic attributes of the stimulus words, length of stimulus chain (dyads or triads), and presentation rate.

Perhaps the most critical differences between these studies were related to the mode of presentation of the stimulus materials. Cermak et al. (1972) presented their stimuli visually, while Pender (1969) presented her stimuli auditorily. Other researchers (Grant \& McCormack, 1969; Hopkins, Edwards, \& Gavelek, 1971) have demonstrated superior performance when stimuli were presented via the auditory modality. Murdock (1968) concluded that the storage systems may be different for visually and auditorily presented material, and Pribram (1969) has posited two parallel systems of encoding and retrieval, one based on spatial and one on temporal encoding. The evaluation dimension results may be dependent on the modality through which the stimuli are presented. It appears that fifth graders have developed the ability to employ opposite values of the evaluation dimension to encode information for future retrieval when the concepts representing that dimension are presented visually. Felzen and Anisfeld (1970) have shown comparable developmental stages in acoustic and semantic encoding in children, with their stage of semantic encoding falling between the third and sixth grades. In contrast to the Cermak et al. (1972) findings, the present investigation suggests that the ability to differentially encode as a function of visually presented evaluative categories is consistent with the ability to label words as belonging to one or the other evaluative category. DiVesta (1966) stated that secondgrade children correctly classified words on the evaluation scale. According to the present findings, fifth graders consistently used this information to aid retrieval when the stimuli were presented visually.

The double shift resulted in no incremental effect beyond the form-shift effect alone. This result supports the position that only form is processed in the double-shift condition and that fifth-grade children encode exclusively along the most salient dimension when a multiple dimension problem is presented. In order to more satisfactorily investigate the question 
of multiple encoding, it will be necessary to continue to isolate two or more salient dimensions which can be simultaneously as well as independently manipulated. It is also necessary to continue to validate the findings of short-term memory research utilizing the Peterson and Peterson (1959) paradigm, with studies investigating the same encoding dimensions but employing alternate paradigms, e.g., false positives in recognition memory (Underwood, 1965), clustering in free recall (Bousfield, Cohen, \& Whitmarsh, 1958), and long-term memory paradigms (Postman, 1961).

\section{Method of Presentation Effect}

While the above results imply that fifth-grade children have developed the ability to employ the form of visual stimulus presentation (picture or word) as an attribute salient to the encoding of information for future retrieval, no evidence is provided regarding the nature of the differences in encoding for words and pictures. Data accumulated in the present study indicate that pictures were consistently more readily recalled than were words $(70 \%$ of the pictures presented on Trials 1-3 were correctly recalled, while only 55\% of the words were correctly recalled across these three trials). Although this result is not directly related to the hypotheses at hand, it is worth discussion. From an empirical point of view, the present discussion may begin with Paivio's (1963) analyses of the abstractconcrete dimension. Concrete nouns have been defined as nouns referring to denotable objects or things, while abstract nouns lack comparable objective referents (Paivio, 1963). Paivio (1963) demonstrated that the learning of noun-adjective paired associates was more rapid than the learning of adjective-noun paired associates. He further demonstrated that learning was more rapid with concrete nouns than with abstract nouns. Paivio's theoretical explanation included the concept that nouns act as "conceptual pegs" from which their modifiers can be hung. Concrete nounadjective pairs evidenced more rapid learning than abstract noun-adjective pairs because concrete nouns were more solid "pegs." In a recent volume, Paivio (1971) noted that objects and pictures were highly concrete by definition. However, he hypothesized that variations in concreteness were even possible between these representational levels, i.e., that one level might be more concrete than another.

Paivio (1963) explained the efficiency of verbal pegs as codes on their capacity to arouse imagery which could mediate recall. Still primarily concemed with demonstrating the significance of imaginal representational processes, Paivio (1971) noted that, to the extent to which imaginal processes are coordinated with abstractness-concreteness, a scaling of items on that dimension would define their capacity to evoke images. A number of studies have involved variation in concreteness entirely at the level of nonverbal representations (Bousfield, Esterson, \& Whitmarsh, 1957; Iscoe \&
Semler, 1964; Jakobovits \& Lambert, 1964). In addition, Wells' (1973) study with adult subjects and the present study with children indicated a generally greater number of correctly recalled pictures than words. Wells (1973) has suggested several possible sources of these differences including: a greater degree of imaginal encoding for pictures, higher informational value of pictures, and variance between the physical character. istics of pictures and their labels. Following Paivio's (1963, 1971) line of reasoning, one may posit that pictures are more concrete than words and therefore serve as greater "conceptual pegs" upon which a greater constellation of associations may be hung. These studies suggest the need to develop a procedure for scaling representational stimuli as they vary along the dimension of concreteness-abstractness.

\section{REFERENCES}

Bousfield. W. A., Cohen. B. Y., \& Whitmarsh, G. A. Associative clustering in the recall of words of different taxonomic frequencies of occurrence. Psychological Reports, 1958. 4. 38.44.

Bousfield. W. A.. Esterson. J.. \& Whitmarsh. G. A. The effects of colored and uncolored pictorial representations on the learning of stimulus words. Journal of Applied Psychology. 1957, 41. 165-168.

Cann, L. F.. Liberty, C., Shafto, M., \& Ornstein, P. A Release from proactive interference with young children. Developmental Psychology, 1973, 8. 396.

Cermak, L. S.. Sagotsky. G., \& Moshier, C. Development of the ability to encode within evaluative dimensions. Journal of Experimental Child Psychology. 1972. 13, 210-219.

DiVEsta. F. J. A developmental study of the semantic structures of children. Journal of Verbal Leaming and Verbal Behavior, 1960. 5. 249-259.

DiVesta. F. J.. \& WAlls, R. T. Factor analysis of the semantic attributes of 487 words and some relationships to the conceptual behavior of fifth-grade children. Journal of Educational Psychology Monograph, 1970, 61(No. 6, Part 2).

Felzen. E., \& ANisfeld. A. Semantic and phonetic relations in the false recognition of words by third- and sixty-grade children. Developmental Psychology, 1970, 3, 163-168.

Goggin. J.. \& Wickens. D. D. Proactive interference and language change in short-term memory. Journal of Verbal Learning and Verbal Behavior, 1971, 10, 453-458.

Grant, K. W.. \& MCCormack, P. D. Auditory and visual short-term memory with successive syllable presentation in both modalities. Psychonomic Science, 1969, 17. 341-342.

Hopkins, R. H., Edwards, R. E., \& Gavelek. J. R. Presentation modality as an encoding variable in short term memory. Journal of Experimental Psychology, 1971. 90. 319.325.

Iscoe. I., \& SEMLER. I. J. Paired-associate learning in normal and mentally retarded children as a function of four experimental conditions. Journal of Comparative and Physiological Psycholog. 1964, 57, 387-392.

JAKOB OVIts. L. A., \& LAMBERT, W. W. Stimulus characteristics as determinants of semantic changes with repeated presentations. American Journal of Psychology, 1964. 77. 84-92.

KEPPEL, G. \& UNDERWood, B. J. Proactive inhibition in short-term retention of single items. Joumal of Verbal Learning and Verbal Behavior, 1962, 1, 153-161.

MURDock, B. B., JR. Modality effects in short-term memory: Storage or retrieval? Joumal of Experimental Psychology, $1968,77,79-86$. 
Osgood, C. E., Suci, G. J., \& Tannenbaum, F. H. The measurement of meaning. Urbana: University of Illinois Press, 1957.

Paivio. A. Imagery and verbal processes. New York: Holt, Rinehart and Winston, 1971.

Paivio, A. Learning of adjective-noun paired associates as a function of adjective-noun word order and noun abstractness. Canadian Journal of Psychology, 1963, 17, 370-379.

Pender. N. J. A developmental study of conceptual. semantic differential, and acoustical dimensions as encoding categories in short-term memory. Final Report on Project 9-E-070. U.S. Department of Health, Education, and Welfare. Northwestern University. 1969.

Peterson, L. R., \& Peterson, M. J. Short-term retention of individual verbal items. Journal of Experimental Psuchology. 1959, 54, 157-173.

Postman. L. The present status of interference theory. In C. N. Cofer (Ed.), Verbal learning and verbal behavior. New York: McGraw-Hill, 1961.

Pribram, K. H. The four Rs of remembering. In K. H. Pribram (Ed.), On the biology of learning. New York: Harcourt. Brace \& World. 1969. Pp. 191-225.

UNDERWOOD, B. J. False recognition produced by implicit verbal responses. Journal of Experimental Psychology, 1965 , 70. $122 \cdot 129$.

Wells, J. E. Words and pictures as distinct encoding categories in short-term memory. Journal of Experimental Psychology, 1973, 97, 394-396.

Wickens, D. D. Characteristics of word encoding. In A. W. Melton and E. Martin (Eds.). Coding processes in human memory. New York: Halstead Press, 1972. Pp. 191-215.

Wickens. D. D. Encoding categories of words: An empirical approach to meaning. Psychological Review, 1970. 77. 1-15.

Wickens, D. D., Born, D. G., \& Allen, C. K. Proactive inhibition and item similarity in short-term memory. Journal of Verbal Learning and Verbal Behavior. 1963. 2. 440-445.

Wickens, D. D., \& ClaAk, S. E. Osgood dimensions as an encoding class in short-term memory. Journal of Experimental Psychology, 1968, 18, 580-584.

WINER, B. J. Statistical principles in experimental design. New York: McGraw-Hill, 1971.

(Received for publication February 12, 1975; revision received May 6, 1975.) 